\title{
Nosocomial Citrobacter Infection in Neonatal Intensive Care Unit in a Hospital of Nepal
}

\author{
Khadka SB ${ }^{1}$, Thapa $\mathrm{B}^{2}$, Mahat $\mathrm{K}^{3}$ \\ ${ }^{1}$ Dr. Sanu Bhai Khadka, MD, MD, Lecturer, Department of Community Medicine, Kathmandu Medical College, \\ Kathmandu, Nepal, ${ }^{2}$ Dr. Badri Thapa, MBBS, Ph.D., Lecturer, Department of Microbiology, Kathmandu Medical \\ College, Kathmandu, Nepal and Genesis Laboratory and Research, Kathmandu, Nepal, ${ }^{3}$ Dr. Kishori Mahat, MBBS, \\ $\mathrm{MPH}$, Genesis Laboratory and Research, Kathmandu, Nepal.
}

Address for correspondence: Dr. B. Thapa, E-mail: badri_bishal@yahoo.com

\begin{abstract}
Introduction: Neonatal Citrobacter infection is either acquired horizontally or vertically as a nosocomial infection. The source of nosocomial Citrobacter is either hands of medical staff or the innate objects. Objective: The aim of this study was to study nosocomial Citrobacter infection in neonates admitted in Neonatal Intensive Care Unit (NICU) and trace the source of infection. Methods: The study was conducted in NICU in a hospital in Kathmandu, Nepal during a period of January to March 2010. Specimens were collected from neonates, hands of medical staff and innate objects and were processed using a standard microbiological method. Results: The prevalence of neonatal nosocomial infection was $32.6 \%$ (29/89). Citrobacter spp. was isolated in 11 neonates admitted in NICU with the prevalence rate of $37.9 \%(11 / 29)$ among other pathogens. Umbilical cord infection was most common $(n=8)$. These isolates were grouped into five antibiotypes (I, 4; II, 3; III, 2; IV, I; V, 1). All of these isolates were multi-drug resistant showing susceptibility towards quinolones. The isolate of Citrobacter spp. was also recovered from a nasal prong which was grouped with 4 other clinical strains. Conclusion: Multi-drug resistant nosocomial Citrobacter spp. was inflicting neonates in NICU and the source of this pathogen was traced to nasal prong. Nosocomial Citrobacter infection is a common problem of neonates in NICU. This will lead to increase neonatal mortality if infection prevention and control practices are not initiated.
\end{abstract}

Key words: Neonates, Citrobacter spp., nasal prong, infection control, Nepal

\section{Introduction}

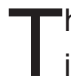
he bacteria of the genus Citrobacter are occasional inhabitants of soil, sewage, water, and food and also an infrequent colonizer of human and animal gastrointestinal tract ${ }^{1}$. In most occasions these Citrobacter spp. are of low virulence and do not cause disease but they can be a source to multiple infections, like respiratory tract, urinary tract, intra-peritoneal, wound, sepsis, meningitis, and brain abscess ${ }^{2}$. This pathogen inflicted neonates in health care settings in 1978 and since then this has emerged as a successful nosocomial pathogen of neonates ${ }^{1-3}$. The surveillance of Citrobacter infection in American medical centers showed the prevalence rate of $0.8 \%$ among Gram negative infections while this accounted for $3-6 \%$ among Enterobacteriaceae in a hospital setting ${ }^{4,5}$. This pathogen is an emerging nosocomial pathogen across the globe $e^{4,6,7}$ and has also been recovered from sputum, surgical wound infection and otitis media in Nepal8-11.

Although, Citrobacter infection has been described in adults, this is also a major problem in neonates admitted in Neonatal Intensive Care Units (NICU) ${ }^{12,13}$. They develop sepsis and meningitis and are at higher risk of developing cerebral abscess. Neonates and infants are also at risk of developing osteomyelitis, septic arthritis, lung abscess, skin infection and urinary tract infection ${ }^{14-18}$.

The infection in neonates are either horizontally transferred as a nosocomial infection or vertically 
transferred from mother during delivery ${ }^{18,19}$. The source of nosocomial Citrobacter infection is attributed to various nate and innate objects (hand of medical staff, water for injection, face mask, nasal prongs, stethoscopes etc.) in $\mathrm{NICU}^{20}$. Septicemia is one of the major killers of neonates, but Citrobacter spp. sepsis has rarely been described in Nepal21,22. Citrobacters along with other pathogens from various specimens were frequently isolated from neonates admitted in NICU of the study site during January to March 2010 . Hence, we studied the nosocomial Citrobacter infections in neonates in NICU in a hospital in Kathmandu, Nepal and traced the source of this pathogen.

\section{Material and Method}

\section{Study settings, samples and bacterial identification}

This cross-sectional study was conducted in Department of Microbiology, Kathmandu Medical College, Kathmandu, Nepal during January to March 2010. Eighty nine clinical samples were collected from 45 nosocomial infected neonates. Neonatal nosocomial and/or NICU acquired infection was defined as infection in new born babies developed after 48 hours of admission in $\mathrm{NICU}^{23}$. Sterile cotton swabs were soaked in sterile normal saline and swabs were taken from hands nursing staff $(n=3)$ and innate objects like, baby cots $(n=11)$, incubator $(n=1)$, face masks $(n=3)$, nasal prong $(n=1)$, stethoscopes $(n=6)$, water for injection $(n=1)$, and intravenous infusion stands $(n=10)$. The samples and swabs collected from neonates were inoculated into Blood agar and MacConkey agar. Swabs taken from hands of nursing staff and innate objects were left into a tube containing Brain Heart Infusion Broth. The inoculated media were incubated at $37^{\circ} \mathrm{C}$ for 24 hours. The blood was inoculated in Brain Heart Infusion broth, incubated at $37^{\circ} \mathrm{C}$ for 24 hours and sub-cultured every 24 hours for 48 hours on Blood agar and MacConkey agar. The organisms grown were identified based on standard phenotypic methods ${ }^{24}$. All media were purchased from Hi-Media Laboratories Pvt. Ltd., India.

Antibiotic susceptibility test: Kirby-Bauer disk diffusion test was performed to assess the in-vitro activity of different antibiotics to the isolated Citrobacter spp. as described before ${ }^{8}$. Briefly, colonies from a grown media were suspended in peptone water to reach the turbidity of $0.5 \mathrm{McF}$ arland standard $\left(\mathrm{BaSO}_{4}\right.$ turbidity standard) and was uniformly streaked on Muller Hinton agar plate. The antibiotic disks were placed over the media. The plate was incubated at $37 \mathrm{C}$ for 18 hours and the zone of inhibition $(\mathrm{mm})$ was measured. The zone size was interpreted based on the guidelines of manufacturer which is based on CLSI guidelines ${ }^{25}$. Muller Hinton agar and antibiotic disks were purchased from Hi-Media Laboratories Pvt. Ltd., India. Multi-drug resistant (MDR) isolates were defined as the isolates that were resistant to two or more than two classes out of three groups of antibiotics; $\beta$-lactams (eg. Piperacillin, ticarcillin, ceftazidime, cefepime, imipenem), amino glycosides (eg. gentamicin, tobramicin) and fluroquinoloones (eg. ciprofloxacin, norfloxacin) ${ }^{25}$.

\section{Results}

\section{Neonatal Citrobacter infections}

Among 89 samples received for bacterial culture, microorganisms were isolated from 29 (32.6\%) samples. Among the culture isolated specimens, 11 (37.9\%) were Citrobacter spp. (Table 1). They were isolated from umbilical swab $(n=8)$, urine $(n=1)$, blood $(n=1)$, and eye swab $(n=1)$. The neonates infected with Citrobacter spp. were all during their first week of life. Klebsiella spp. $(\mathrm{n}=5)$, Escherichia coli $(\mathrm{n}=4)$, Acinetobacter spp. $(\mathrm{n}=3)$, Proteus spp. $(\mathrm{n}=2)$, Enterobacter spp. $(\mathrm{n}=1)$ and Staphyloccous aureus $(n=3)$ were identified by culture and using biochemical properties.

\section{Citrobacter spp. from nate and innate objects}

Most Citrobacter infections in NICU were noscomial borne hence to detect the source of Citrobacter spp. several samples from nate and innate objects were collected and processed. Among several innate objects studied Citrobacter spp. was recovered from a nasal prong. Staphylococcus aureus was also isolated from baby cots $(n=2)$ and incubator. Acinetobacter spp. was isolated from water for injection. Hands of nursing staff and other innate objects were free from pathogenic organisms.

\section{Antibiotic Susceptibility pattern and Antibiotypes}

All of the isolates isolated from neonates and nasal prong showed MDR phenotype (Table 1). Most of these isolates were sensitive to quinolones tested $(n=11)$. Among the $\beta$-lactam antibiotics tested, Ceftriaxone and Amoxycillin and Clavulenic Acid combination was sensitive to 5 and 1 isolate respectively. Based on the antibiotic sensitivity pattern these Citrobacte spp. were grouped into 5 antibiotypes (I to V). Citrobacter spp. isolated from a nasal prong (C109) had a similar antibiotype with 4 other Citrobacter spp. isolated from neonates. Antibiotype type IV (C3409) was resistant to all the antibiotics tested. 
Table 1. Antibiotic susceptibility patterns of Citrobacter spp. from various specimens in neonates.

\begin{tabular}{|c|c|c|c|c|}
\hline Identification no. & Age (days) & Specimen & Antibiotypes & Sensitive to \\
\hline C11709 & 5 & US & \multirow{5}{*}{1} & \multirow{5}{*}{ OF, CF, NX } \\
\hline C52809 & NA & US & & \\
\hline C54109 & 4 & $U$ & & \\
\hline C316709 & NA & US & & \\
\hline C109 & NA & NP & & \\
\hline C12309 & NA & US & \multirow{3}{*}{ II } & \multirow{3}{*}{$\mathrm{Cl}, \mathrm{AK}, \mathrm{NT}, \mathrm{CF}, \mathrm{OF}, \mathrm{NX}$} \\
\hline C27309 & 5 & US & & \\
\hline C40809 & 6 & US & & \\
\hline C24309 & 4 & ES & \multirow{2}{*}{ III } & \multirow{2}{*}{$\mathrm{Cl}, \mathrm{OF}, \mathrm{CF}, \mathrm{NX}$} \\
\hline C32209 & 4 & US & & \\
\hline C3409 & NA & US & IV & None \\
\hline C21809 & NA & $\mathrm{BL}$ & $\mathrm{V}$ & $\mathrm{CA}, \mathrm{OF}, \mathrm{AK}, \mathrm{NT}$ \\
\hline
\end{tabular}

Eleven antibiotics ( $\mu \mathrm{g} / \mathrm{disk}$ ) tested were, Ampicillin (A) (10), Piperacillin (PC) (100), Amoxy-Clavulenic Acid (CA) (20/10), Ceftriaxone (Cl) (30), Cephalexin (CP) (30), Amikacin (AK) (30), Netilmicin (NT) (30), Ciprofloxacin (CF) (5), Ofloxacin (OF) (5), Norfloxacin (NX) (10), and Sulpha/Trimithorpim (CO) (23.75+1.25), U, Urine; US, Umbilical Swab; ES, Eye Swab; BL, Blood; NP, Nasal Prong; "NA“, age not available.

\section{Discussion}

Hospital acquired infection is a major threat to hospitalized neonates causing high morbidity and mortality in developing countries ${ }^{26}$. During the period of study, the rate of nosocomial neonatal infection was $32.6 \%$ and Citrobacter spp. was most frequently isolated $(n=11)$. The prevalence rate was $37.9 \%$ among the pathogens infecting neonates. Staphylococcus aureus (38\%), coagulase negative Staphyloccous spp. (21\%), E. coli and Enterobacter spp. were isolated as nosocomial pathogens in sepsis in a hospital in Nepal ${ }^{21}$. High prevalence of Citrobacterspp. in this study highlights the emergence of this pathogen as a successful nosocomial pathogen. Acinetobacter spp., E. coli, Proteus spp., Klebsiella spp., Enterobacter spp., and Staphylococcus aureus were also isolated from neonates albeit at low prevalence. Umbilical cord infection was most common $(n=8)$ while each of three neonates had sepsis, urinary tract infection and ophthalmitis. Umbilical cord infection was also most common in newborns in a community based study on Southern Nepal and this infection could be more in neonates born in the hospital where infection control is compromised ${ }^{27}$. Citrobacter meningitis leading to brain abscess is commonly encountered in NICU but none of the neonates had this disease $\mathrm{e}^{12,13}$.

Citrobacter spp. is carried in the hands of medical staff and in innate objects present in the hospital ward ${ }^{20}$. When babies are handled by the colonized medical staffs or procedures (catheterization, opening intravenous lines, giving intravenous fluids and antibiotics, oxygen delivery through face mask and nasal prongs etc.) are carried on these neonates, bacteria are introduced inside the body leading to multiple diseases. To investigate the source of Citrobacter spp. in NICU, various samples from the hands of medical staff and innate objects were colleted. Citrobacter spp. was recovered from a nasal prong which had similar antibiotype to 4 other Citrobacters belonging to antibiotype I. This pathogen was the source of infection to these neonates admitted to NICU based on antibiotyping. However, antibiotyping is not a reliable tool to investigate the clonal relationship and robust molecular typing tools are needed ${ }^{28}$. Acinetobacter spp. was also isolated from water for injection and Staphylococcus aureus was isolated from two baby cots but the antibiotic resistance pattern did not match with the clinical isolates. The duty doctor and nursing staffs were notified on time to prevent the further spread of these pathogens in NICU.

The Citrobacters isolated were MDR and antibiotype IV was resistant to all antibiotics tested. Most of these isolates were resistant to common antibiotics used for treatment like, $\beta$-lactams and aminoglycosides. However, Citrobacter spp. isolated from neonates were sensitive to quinolones. The present study was supported by the documentation of MDR strains of Citrobacter spp. from sputum from a hospital in Kathmandu but these strains were susceptible to cefoperazone and sulbactam combination ${ }^{8}$. This combination was not tested in the present study so we could not know the sensitivity of this combination. Citrobacters isolated from children in Manipal College of Medical Science, Nepal also showed resistance to $\beta$-lactams, amino glycosides and also to quinolones ${ }^{29}$. The strains of Citrobacter spp. resistant to these antibiotics and even to carbapenems have been noticed outside $\mathrm{Nepal}^{7,30}$. If newer generation 
antibiotics like, carbapenems, colistin and tigecycline are prescribed without antibiotic prescribing policies the resistant Citrobater may emerge leading to therapeutic deadlock. This study highlights the need for nosocomial infection prevention and control to decrease Citrobacter morbidity and mortality among neonates.

\section{Conclusion}

Nosocomial Citrobacter infection was common among neonates admitted in NICU and the source of this infection was nasal prong. The frequent isolation of this pathogen in NICU with growing antibiotic resistance raises a threat to this present antibiotic era and is a concern for all physicians involved in the treatment. If infection prevention and control practices are not initiated nosocomial Citrobacter could be the major cause of neonatal mortality in NICU in this hospital.

Acknowledgements: Authors would like to thank all patients and staff in Neonatal Intensive Care Unit of the study site.

\section{Funding: None. \\ Conflict of Interest: None. \\ Permission from IRB: Yes.}

\section{References}

1. Smith A, Saiman L, Zhou J, Della-Latta $P$, Jia $H$, Graham PL. Concordance of gastrointestinal tract colonization and subsequent blood stream infections with Gram negative bacilli in very low birth weight infants in the Neonatal Intensive Care Unit. Pediatr Infect Dis J 2010;29:831-5.

2. Hodges GR, Degener CE, Barnes WG. Clinical significance of Citrobacter isolates. Am J Clin Pathol 1978;70:37-40.

3. Christo GG, Mathai J, Nalini B, Baliga M, Venkatesh A. Neonatal Citrobacter sepsis: clinical and epidemiological aspects. Indian $J$ Pediatr 1990;57:781-4

4. Jones RN, Jenkins SG, Hoban DJ, Pfaller MA, Ramphal R. In vitro efficacy of six cephalosporins tested against Enterobacteriaceae isolated at 38 North American medical centres participating in the SENTRY antimicrobial surveillance program, 1997-1998. Int J Antimicrob Agents 2000;15:111-8.

5. Lavigne JP, Defez C, Bouziges N, Mahamat A, Sotto A. Clinical and molecular epidemiology of multidrug-resistant Citrobacter spp. infections in a French University Hospital. Eur J Clin Microbiol Infect Dis 2007;26:439-441.
6. Samonis G, Karageorgopoulos DE, Kofteridis DP, Matthaion DK, Sidiropoulou V, Maraki S et al. Citrobacter infections in a general hospital: characteristics and outcomes. Eur $J$ Infect Dis 2009;28:61-8.

7. Diekema DJ, Pfaller MA, Jones RN, Doern GV, Kugler KC, Beach ML et al. Trends in antimicrobial susceptibility of bacterial pathogens isolated from patients with bloodstream infections in the USA, Canada and Latin America. Int J Antimicrob Agents 2000;13:257-71.

8. Thapa B, Adhikari P, Mahat K, Chetteri MR, Joshi LN. Multidrug-resistant nosocomial Citrobacter in a hospital in Kathmandu. Nepal Med Coll J 2009;11;195-99.

9. Banjara MR, Sharma AP, Hoshi AB, Tuladhar NR, Ghimire P, Bhatta DR. Surgical wound infections in patients of Tribhuvan University Teaching Hospital. Nepal Health Res Counc 2003;3;41-5.

10. Kansakar P, Pokherel BM, Tuladhar NR. A study on bacteriology of wound infection and the antibiotic sensitivity pattern of the isolates. Fourth congress of association of clinical pathologists of Nepal (ACPN) February 21-2, Souvenir 2003;35.

11. Jha AK, Singh JB, Dutta D. Microorganisms present in discharging otitis media in a group of patients in Kathmandu. Nepal Med Coll J 2007;9:196-8.

12. Azrak M, Augustini MD, Fernandez Z, Peruffo MV, Malvaso R. Citrobacter koseri brain abscess in an infant. Case report and literature review. Arch Argent Pediatr 2009;107:542-56.

13. Tang LM, Chen ST, Lui TN. Citrobacter meningitis in adults. Clin Neurol Neurosurg 1994;96:52-7.

14. Jansen RD, Meadow WL, Schwartz IK, Ogata ES. "Bacteriological bit", Citrobacter diversus osteomyelitis in a neonate. Clin Pediatr (Phila) bacterio1 1981;20:791.

15. Bruehl CL, Listernick R. Citrobacter freundii septic arthritis. J Paediatr Child Health 1992;28:402-3.

16. Shamir R, Horev G, Merlob P, Nutman J. Citrobacter diversus lung abscess in a preterm infant. Pediatr Infect Dis J 1990;9:221-2.

17. Barton LL, Walentik C. Citrobacter diversus urinary tract infection. Am J Dis Child 1982;136:467-8.

18. Mohanty S, Singhal R, Sood S, Dhawan B, Kapil A and Das BK. Citrobacter infections in a tertiary care hospital in Northern India. J Infect 2007;54:58-64. 
19. Papasian CJ, Kinney J, Coffman S, Hollis RJ, Pfaller MA. Transmission of Citrobacter koseri from mother to infant documented by ribotyping and pulsed-field gel electrophoresis. Diag Microbiol Infect Dis 1996;26:63-7.

20. Parry MF, Hutchinson $\mathrm{JH}$, Brown NA, $\mathrm{Wu} \mathrm{CH}$, Estreller L. Gram-negative sepsis in neonates: a nursery outbreak due to hand carriage of Citrobacter diversus. Pediatrics 1980;65:1105-09.

21. Shrestha $P$, Das BK, Bhatta NK, Jha DK, Das B, Setia A et al. Clinical and bacteriological profiles of blood culture positive sepsis in newborns. J Nepal Paediatr Soc 2007;27:64-7.

22. Jain NK, Jain VM, Maheshwari S. Clinical Profile of Neonatal Sepsis. Kathmandu Univ Med $J$ 2003;1:117-20

23. South Australian Health care associated multi-drug resistant organisms surveillance report. 20062008.p-22.

24. Monica C. District laboratory practices in tropical countries. Part 2. $2^{\text {rd }}$ ed. USA (NY): Cambridge University Press; 2006.

25. Clinical and Laboratory Standards Institute. Performance standards for antimicrobial susceptibility testing; 15 th informational supplement.
CLSI document M100-S15. Clinical and Laboratory Standards Institute, Wayne, PA.

26. Vergnano S, Sharland M, Kazembe P, Mwansambo C, Heath PT. Neonatal sepsis: an international perspective. Arch Dis Child Fetal Neonatal Ed 2005;90:F220-24

27. Mullany LC, Darmstad GL, Katz J, Khatry SK, LeClerq SC, Adhikari RK et al. Risk factors for umbilical cord infection among newborns of Southern Nepal. Am J Epidemiol 2006;20:203-11.

28. Norskov-Lauritsen N, Sandvang D, Hedegaard J, Fussing HV, Mortensen KK, Sperling-Peterson $\mathrm{HU}$ et al. Clonal origin of amino glycoside-resistant Citrobacter fruendii isolates in Danish county. $J$ Med Microbiol 2001;50:636-41.

29. Malla KK, Sarma MS, Malla T, Thapalial A. Clinical profile, bacterial isolates and antibiotic susceptibility patterns in urinary tract infection in children-hospital based study. J Nepal Paediatr Soc 2008;28:52-61.

30. Lockhart SR, Abramson MA, Beekmann SE, Gallagher G, Riedel S, Diekema DJ et al. Antimicrobial resistance among Gram-negative bacilli causing infections in intensive care unit patients in the United States between 1993 and 2004. J Clin Microbiol 2007;45:3352-9.

\section{How to cite this article?}

Khadka SB, Thapa B, Mahat K. Nosocomial Citrobacter Infection in Neonatal Intensive Care Unit in a Hospital of Nepal. J Nep Paedtr Soc 2011;31(2):105-109. 